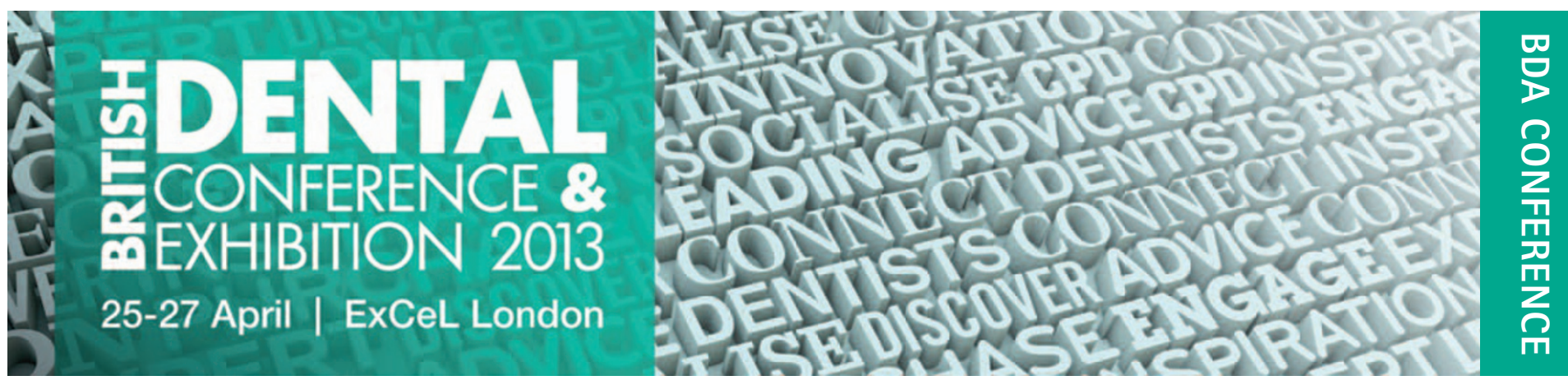

\title{
Radiographic selection criteria: new guidelines, old challenges
}

\section{K. Horner ${ }^{1}$}

Radiographic selection criteria are a legal requirement for any establishment using ionising radiation for medical purposes, including dental practices. The Faculty of General Dental Practice (UK) pioneered the development of radiographic selection criteria for dentistry in the UK in 1998 and followed this with a second edition in 2004. This year will see a third edition, updated by new research evidence and developments in X-ray imaging for dentistry, including cone beam computed tomography (CT). Radiographic selection criteria are not rules but are one form of clinical guideline designed to help in clinical decision making. There are many influences on the use of radiography in dental practice including non-clinical factors. Evidence-based radiographic selection criteria can help to reinforce good practice, but require a multi-faceted implementation strategy including incorporation into clinical audit, easy availability to users and education.

\section{INTRODUCTION}

It is accepted that $\mathrm{X}$-ray exposure involves a risk, so it is essential that any $\mathrm{X}$-ray examination should show a potential net benefit to the patient, weighing the total diagnostic benefits it produces against the detriment that the exposure might cause. The efficacy, benefits and risk of available alternative techniques having the same objective but involving less (or no) exposure to X-rays should be taken into account. This decision-making process is called 'justification' and is both an ethical ${ }^{1}$ and a legal requirement. ${ }^{2}$

Weighing benefits against risks is easier said than done. Dental use of radiography carries very low risks. Compared, however, with other uses of X-rays in medicine, it also involves relatively low benefits. In everyday dentistry how many of us spend time musing over the

Professor of Oral and Maxillofacial Imaging, University of Manchester, School of Dentistry, Coupland III Building, Coupland Street, Manchester, M13 9PL Correspondence to: Professor Keith Horner Email: keith.horner@manchester.ac.uk

DOI: $10.1038 / s j . b d j .2013 .158$

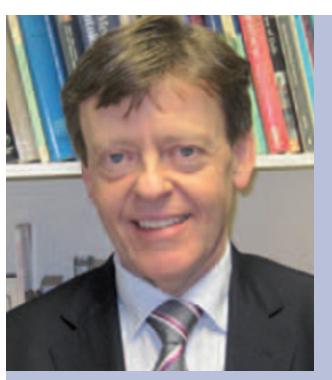

Keith Horner is Professor of Oral and Maxillofacial Imaging at the University of Manchester, honorary consultant in dental and maxillofacial radiology at Central Manchester University Hospitals NHS Foundation Trust and a registered specialist in dental radiology. He combines academic research and teaching with clinical work. His clinical work includes running a hospital-based cone beam CT service with referrals from regional hospitals and private dental practitioners. Professor Horner's research includes bone density and osteoporosis, and aspects of radiation protection in dental imaging. He also has a long-standing interest in clinical guideline development, and he has been involved with the FGDP(UK) Selection Criteria for Dental Radiography guidelines in both previous editions and is co-editor for the new edition. Recently, he was co-ordinator of the European Commission-funded SEDENTEXCT project, dealing with safety and efficacy of dental cone beam CT, which culminated in the publication of European evidence-based guidelines in 2012. He was also a member of the European Association for Osseointegration consensus workshop on guidelines on imaging for implant dentistry in 2011.

arcane question of whether the benefit of a panoramic radiograph outweighs a tiny risk of inducing cancer? While the presence of a radiation risk should never be forgotten, a more practical approach is to look at X-ray imaging as a tool to help solve problems. The right tool, at the right time, will improve the chances of success. In contrast, taking the wrong radiograph, using imaging too frequently or never taking the correct radiograph can result in poor patient care and unnecessary healthcare costs. Thus it is also important to look at choices in radiography as a consumer issue for the patient.

\section{GUIDELINES}

Guidelines are sometimes misinterpreted as rules but have been sensibly defined as "systematically developed statements to assist practitioner and patient decisions about appropriate healthcare for specific clinical circumstances. ${ }^{3}$ Each year an enormous number of research 
papers are published. Some research is excellent and some is flawed. Research papers may contain nuggets of information which could usefully influence practice, yet the average practitioner cannot be expected to read everything, judge its value and decide on whether the assimilated evidence should change patient care. Guidelines, if appropriately produced and regularly updated, can allow the practitioner a fast track access to the evidence. Over and above this, having guidelines can be a valuable weapon against eccentric practices and a means of reducing healthcare costs by avoiding unnecessary interventions.

An important aspect of guidelines is their quality. Methods of developing guidelines include 'expert panels', consensus processes of larger groups of stakeholders through to formal evidencebased development using systematic reviews. The use of small expert panels is a relatively weak method, as it can be viewed as an old boys' network intent on reinforcing their own biased views. Unfortunately, where research evidence is weak or non-existent, a panel of experts may be the only available approach. An evidence-based approach should always be aspired to, as the well-established methodologies (for example, NICE or SIGN methods ${ }^{4,5}$ ) offer the best chance of eliminating bias.

\section{Radiographic guidelines}

While guidelines related to radiology often deal with safety aspects of using $\mathrm{X}$-rays, a key aspect is justification. 'Selection criteria' are descriptions of clinical conditions, derived from patient signs, symptoms and history, that identify patients who are likely to benefit from a particular radiographic technique; their role is to assist in the justification process. There is a legal requirement in the UK that every dental practice using $\mathrm{X}$-rays should have radiographic selection/referral criteria. ${ }^{2}$

In the UK, the first edition of the FGDP(UK) Selection Criteria for Dental Radiography, published in 1998, set out to achieve much at a time when dental services and practices were evolving and when new research evidence was constantly being produced. A second edition, published in 2004, presented an update

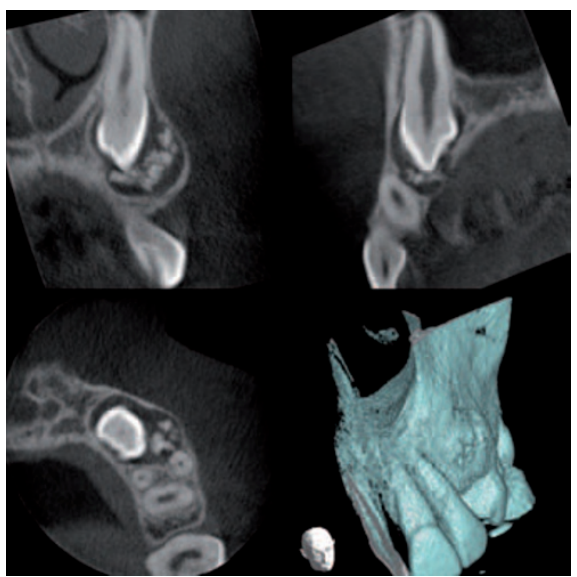

Fig. 1 A cone beam CT scan of an unerupted maxillary canine tooth associated with a compound odontome. The question is whether this kind of 'three-dimensional' information, compared with traditional radiography, changes outcomes for patients or whether it only provides dentists with attractive images

incorporating new evidence and developments, including the more widespread use of digital radiography. ${ }^{6}$ Since then, there have been a number of developments and some enhancement of the level of evidence to support recommendations. One particular development since the second edition has been the increasing availability of cone beam computed tomography (CBCT) (Fig. 1). This technique is typically associated with radiation doses which are an order of magnitude greater than conventional radiographic techniques. ${ }^{7}$ Thus justification of CBCT examinations requires clear evidence of increased benefits to patients. The third edition continues the process of review and evolution of the guidelines, taking such developments into consideration.

Dentistry presents unique challenges to the justification process in radiation protection. Many dentists simply prescribe radiographs according to a personal routine, but there is ample evidence that these routines vary enormously, even within small geographic areas with a shared level of oral health and disease prevalence. Financial factors appear to be influential in use of radiology, as do other non-clinical factors such as medico-legal concerns and patient pressure. ${ }^{8,9}$ Without easy access to specialist radiology and medical physics support, dental practitioners could be more easily influenced by manufacturers' advertising about supposed radiation doses and clinical usefulness of imaging. 'Screening' panoramic radiography has little evidence of efficacy and its use as the primary imaging method for caries detection does not match the research evidence of inferior diagnostic accuracy. ${ }^{10}$ Should endodontic and other treatments be reviewed radiographically and, if so, how often? Is it justifiable to check the development of children's teeth using radiography? Is it true, as some have suggested, that 'you can't have too much information' and that routine, regular, comprehensive radiographic examination is the right approach?

\section{The new FGDP(UK) guidelines}

To those familiar with the two previous editions, the format of the new FGDP(UK) Selection Criteria for Dental Radiography will be familiar. The document is divided up into sections (for example, caries, periodontal, developing dentition, etc) with a précis of current knowledge and guideline recommendations marked with an evidence grade arrived at using SIGN methodology. ${ }^{5}$ Each section has been prepared by two experts, but with as much of an evidence-based approach as possible. In spite of the publication of a substantial volume of research on dental $\mathrm{X}$-ray imaging since the second edition, the level of evidence for the choice of particular types of imaging in the oral cavity is sometimes still supported by clinical opinion rather than hard science. Cases where there is little evidence to support one type of radiography over another are highlighted throughout this document.

A new departure in this edition is a section providing an imaging strategy for the dentate or partially dentate adult patient. In many respects this can be seen as the core of the document for the majority of adult patients. Apart from this, the most obvious changes are in recommendations concerning CBCT. Despite the technique's development being in the context of implant dentistry, it is becoming increasingly used in a wide range of clinical situations, notably in endodontic and orthodontic practice, often on the basis of sparse research evidence. ${ }^{7}$ For most UK dentists, CBCT remains something of which they may be aware but to which they have no access. Experience in other 
countries suggests that this situation will change rapidly and the new edition of the guidelines will be, for a few years at least, ahead of the game.

\section{DOES ANYONE FOLLOW GUIDELINES?}

While there is a sound rationale for having selection criteria for dental X-ray imaging, the sparse evidence on awareness of guidelines and their effect on practice are not encouraging. ${ }^{11,12}$ The paucity of evidence for some guidelines can result in striking differences between selection criteria in the UK and those in other countries. Disagreement in guidelines is hardly something which inspires confidence in clinicians. So are those of us promoting guidelines just voices crying in the wilderness? Well, I hope not. There is no well-established way of ensuring evidence-based guidelines are implemented in practice, although combinations of actions, including publicity, easy access and incorporation into clinical audit, are recommended ${ }^{13}$. The most valuable way forward, however, remains education, particularly at undergraduate level when the use of guidelines in general, and radiographic selection criteria in particular, can be introduced as normal practice.

\section{CONCLUSION}

Radiographic selection criteria are an essential tool in radiation protection and we are required to have them in our practices. Beyond this requirement, they can be a valuable means of translating research evidence into everyday clinical practice which should help our patients. The new FGDP(UK) Selection Criteria for Dental Radiography document builds on the success of previous editions and should be valid for some years before a fourth edition will prove to be necessary. Think of the document as a 'radiologist in your pocket', available for an opinion on imaging choices at any time; you don't have to follow the advice, but it will give you a feel for what the evidence suggests we should be doing.

1. International Workshop on Justification of Medical Exposure in Diagnostic Imaging 2009, Brussels, Belgium. Justification of medical exposure in diagnostic imaging: Proceedings of an International Workshop on Justification of Medical Exposure in Diagnostic Imaging. Workshop organised by the International Atomic Energy Agency in cooperation with the European Commission and held in Brussels, 2-4 September 2009. Vienna: International Atomic Energy Agency, 2011. Online proceedings available at http://www-pub.iaea. org/MTCD/Publications/PDF/Pub1532_web.pdf (accessed February 2013).

2. The lonising Radiation (Medical Exposure) Regulations 2000. SI 2000 No 1059. London: the Stationery Office, 2000. ISBN 011 099: 1311.

3. Field M J, Lohr K N. Guidelines for Clinical Practice: from development to use. Washington DC: National Academic Press, 1992.

4. National Institute for Health and Clinical Excellence. The guidelines manual. London: National Institute for Health and Clinical Excellence, 2012. Available from: www.nice.org.uk.

5. Scottish Intercollegiate Guidelines Network (SIGN)
A guideline developers' handbook. Edinburgh: SIGN, 2008. Report No: 50

6. Faculty of General Dental Practitioners (UK). Selection criteria for dental radiography. 2nd ed. London: Faculty of General Dental Practitioners (UK), 2004.

7. European Commission 2012. Radiation Protection 172. Evidence Based Guidelines on Cone Beam CT for Dental and Maxillofacial Radiology. Office for Official Publications of the European Communities: Luxembourg, 2012. Online guidelines available at http://ec.europa.eu/energy/ nuclear/radiation_protection/doc/publication/172. pdf (accessed February 2013).

8. Tickle M, McDonald R, Franklin J, Aggarwal V R, Milsom K, Reeves D. Paying for the wrong kind of performance? Financial incentives and behaviour changes in National Health Service dentistry 1992-2009. Community Dent Oral Epidemio/ 2011; 39: 465-473.

9. Rushton V E, Horner K, Worthington H V. Factors influencing the frequency of bitewing radiography in general dental practice. Community Dent Oral Epidemiol 1996; 24: 272-276.

10. Rushton M N, Rushton V E. A study to determine the added value of 740 screening panoramic radiographs compared to intraoral radiography in the management of adult ( $>18$ years) dentate patients in a primary care setting. $J$ Dent 2012; 40: 661-669.

11. Mauthe P W, Eaton K A. An investigation into the bitewing radiographic prescribing patterns of West Kent general dental practitioners. Prim Dent Care 2011: 18: 107-114.

12. Kim M, Mupparapu M. Dental radiographic guidelines: a review. Quintessence Int 2009; 40: 389-398

13. Francke A L, Smit MC, de Veer A J, Mistiaen P. Factors influencing the implementation of clinical guidelines for health care professionals: A systematic meta-review. BMC Med Inform Decis Mak 2008; 8: 38.

Keith Horner will be speaking on this topic on Friday 26 April at the 2013 British Dental Conference \&t Exhibition, held at ExCeL London. Register online: www.bda.org/conference 